\title{
Last-minute reprieve for Canada's research lakes
}

\section{Government strikes temporary deal with independent institute to keep freshwater experimental site open.}

\section{Brian Owens}

02 September 2013

Canada's world-renowned Experimental Lakes Area (ELA) has been saved from imminent closure after the federal government signed a makeshift 11th-hour deal with the International Institute for Sustainable Development (IISD) to take over the running of the facility.

Effective from 1 September to at least March next year, the Winnipeg-based IISD will assume responsibility for scientific work from the federal Department of Fisheries and Oceans (DFO), whose decades-old agreement with the province of Ontario to run the ELA expired on that day.

"I am thrilled that the Experimental Lakes Area will remain open. The research performed here provides invaluable knowledge about climate change and helps protect freshwater systems around the world. I want to thank all parties for working together to help make Ontario a world-class destination for scientific research," said Ontario premier Kathleen Wynne in a statement.

The province of Ontario will provide the bulk of the $\$ 3$ million a year needed to run the research site, which consists of 58 lakes and a laboratory complex in the wilds of northern Ontario. Its home province has committed \$2m a year, with Manitoba and the DFO agreeing to chip in. The IISD is also planning to raise money to help cover the running costs.

Scott Vaughan, president of the IISD, told Nature that the institute plans to have 12 scientists at ELA, and will offer the lab's current employees the opportunity to

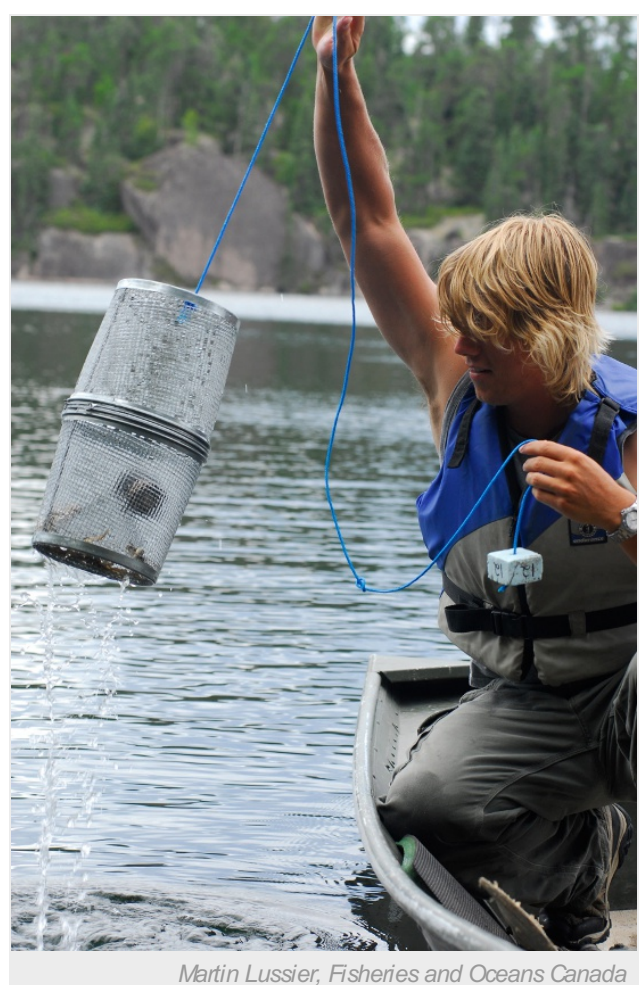

Research at the Experimental Lakes Area has provided valuable data about ecosystems and pollution. continue working at ELA as IISD staff. The agreement will run until March, during which time the DFO will clean up the site, and the IISD will continue to work on negotiating a long-term deal with the province and federal government, says Vaughan.

Diane Orihel, one of the founders of Save the ELA, a pressure group headquartered in Winnipeg, Manitoba, says that the scientific community is grateful to Ontario and the IISD for stepping in to save the facility, but notes that the new agreement is still only temporary. "This is another stop-gap measure," she says. "The federal government has once again failed in its promise to transfer control of the ELA."

In May 2012, the federal government announced that it would shut down the ELA at the end of that financial year in March 2013 (see 'Canada's renowned freshwater research site to close'). The announcement sparked an international outcry in support of the research station, which has been running since 1968, and whose work on acid rain contributed to international treaties regulating industrial emissions. A petition calling for the ELA to be kept open gathered 30,000 signatures.

The government said it would try to find a new operator for the facility, but there was little progress on that front until April this year, when Wynne announced that Ontario would step in with \$2 million a year to keep the ELA open, and would take the lead on negotiations to transfer ownership to the IISD (see 'Glimmer of hope for freshwater research site').

The turmoil has meant that little scientific work beyond routine monitoring has been done for the past two years. Maggie Xenopoulos, an ecologist at Trent University in Peterborough, won a three-year, $\$ 800,000$ grant in October 2011 to study the environmental effects of nanosilver particles commonly used for the antimicrobial properties in clothing and food containers. 
the experiments and was a partner in the research — did not want to assume the liability for it. They were allowed to continue monitoring the lakes this year, but Xenopolous is not sure if she will be able to do the whole-ecosystem work even if the ELA is saved. "The funding is only for three years, and the first year-and-a-half of it is gone, spent," she says.

This is exactly the kind of research that Vaughan hopes the IISD will be able to support at ELA. "One of our core areas is freshwater management," he says. "By inviting ELA in, it gives us one of the world's leading diagnostic capacities, and the only whole-lake research system." But there are still some obstacles to be overcome. The IISD wants assurances that experiments that involve adding pollutants to the lakes will not break the law, which will likely require changes in both federal and provincial environmental regulations. A remediation fund will also need to be set up, to pay for any clean-up.

Orihel hopes that those details can be resolved quickly, so that whole-ecosystem research like Xenopoulos' can resume. "We've already lost two field seasons," she says. "How many years will it be until we can start doing real research again?"

Nature | doi:10.1038/nature.2013.13660 